\title{
Neodymium-based Conversion Coating on AZ31 Magnesium Alloy
}

\author{
Zhao Dingzang1, $\quad$ Zhang Dingfei ${ }^{1,2}, \quad$ Liu Yuping ${ }^{3}, \quad$ Hu Guangshan ${ }^{1}, \quad$ Gou Yinning ${ }^{1,4}$, \\ Pan Fusheng ${ }^{1,2}$
}

${ }^{1}$ College of Materials Science and Engineering, Chongqing University, Chongqing 400045, China; ${ }^{2}$ National Engineering Research Center for Magnesium Alloys, Chongqing University, Chongqing 400044, China; ${ }^{3}$ College of Chemistry and Chemical Engineering, Chongqing University, Chongqing 400044, China; ${ }^{4}$ Chongqing University of Technology, Chongqing 400054, China

\begin{abstract}
A neodymium-based (Nd-based) conversion coating was obtained on the surface of AZ31 magnesium alloy. The formation process of the Nd-based conversion coating was examined by a weighing experiment and an open circuit potential (OCP) test. The coating morphology, microstructure and composition were characterized by scanning electron microscopy (SEM), energy dispersive spectroscopy (EDS), X-ray photoelectron spectroscopy (XPS) and X-ray diffraction (XRD), respectively. The variation of morphology for the bare sample and the coated sample immersed in $3.5 \mathrm{wt} \% \mathrm{NaCl}$ aqueous solution was investigated. The results show that the Nd-based conversion coating can effectively reduce the corrosion speed in $3.5 \mathrm{wt} \% \mathrm{NaCl}$ aqueous solution. The composition and corrosion resistance of Nd-based conversion coating after post-treatment were measured by XRD and electrochemical experiments. The post-treatment can perfectly improve the corrosion resistance of the Nd-based conversion coating.
\end{abstract}

Key words: AZ31 Mg alloy; neodymium-based conversion coating; formation process; corrosion; post-treatment

Magnesium alloy has attracted considerable attention for application in various engineering sections where weight saving is desired, primarily due to its highly desirable performance characteristics such as low density and high specific strength ${ }^{[1,2]}$. However, it is well documented that $\mathrm{Mg}$ alloy suffers limited environmental endurance when exposed in the atmosphere for its poor anti-corrosion performance $^{[3,4]}$. It is thus of great significance to develop a feasible approach to enhance the corrosion resistance of $\mathrm{Mg}$ alloy and a multitude of literatures concerning this topic is currently available indeed.

Previously, investigations have been made to enhance the anti-corrosion resistance of $\mathrm{Mg}$ alloys ${ }^{[5-7]}$. Chemical conversion coatings for $\mathrm{Mg}$ have attracted great attention in the field of anti-corrosion resistance of $\mathrm{Mg}$ alloys ${ }^{[8-11]}$. For environmental friendliness and legislation regarding toxicity, many new conversion coatings have become attractive procedures to decrease the corrosion rate of $\mathrm{Mg}$ alloys instead of toxic chromate ions in recent years. Birbilis et al. ${ }^{[12]}$ developed a surface film upon pure $\mathrm{Mg}$ in ionic liquid, which is promising in terms of continual development of corrosion protection strategies. Chen et al. ${ }^{[13]}$ reported a double-layered $\mathrm{Mn}^{2+}-\mathrm{PO}_{4}$ conversion coating onto die-cast AZ91D Mg alloy and took insights into coating formation, growth and corrosion resistance. Other conversion coatings, such as organic compounds ${ }^{[14]}$, phosphate $^{[15]}$, and stannate ${ }^{[16,17]}$, have been studied to improve the corrosion resistance of $\mathrm{Mg}$ alloy.

Rare earth ions, as $\mathrm{La}^{3+}, \mathrm{Ce}^{3+}$, and $\mathrm{Nd}^{3+}$, forming insoluble hydroxides, have been revealed to be an effective protection system of $\mathrm{Mg}$ alloy ${ }^{[18]}$. Jin et al. ${ }^{[19]}$ reported neodymium conversion coatings upon AZ91D, and

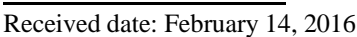

Foundation item: National Great Theoretic Research Project (2013CB632200); International Cooperation Project (2010DFR50010); Chongqing Sci \& Tech Support Project (CSTC2013jcyjC60001); Sharing Fund of Chongqing University's Large-Scale Equipment

Corresponding author: Zhang Dingfei, Ph. D., Professor, School of Materials Science and Engineering, Chongqing University, Chongqing 400045, P. R. China, Tel: 0086-23-65112491, E-mail: zhangdingfei@cqu.edu.cn

Copyright ( 2017, Northwest Institute for Nonferrous Metal Research. Published by Elsevier BV. All rights reserved. 
observed the formation and growth of $\mathrm{Nd}$ conversion coatings. Levy ${ }^{[20]}$ obtained an initial $\mathrm{Nd}$ layer on $\mathrm{Mg}-\mathrm{Nd}-\mathrm{Y}-\mathrm{Zr}-\mathrm{Ga}$ alloy and analyzed the composition of the conversion coatings. Compared with the mature system of cerium conversion coatings, the formation mechanism, performance in corrosive medium and post-treatment of neodymium conversion coatings were worth lucubrating.

In the present study, a Nd-based conversion coating on AZ31 Mg alloys was prepared in neodymium nitrate solution with additives using a selected forming process by orthogonal experiments. The formation process, morphology, composition and performance in $3.5 \mathrm{wt} \% \mathrm{NaCl}$ solution of Nd-based conversion coatings were investigated. The influence of sol-gel post-treatment on Nd-based conversion coating was explored.

\section{Experiment}

AZ31 Mg alloy with a chemical composition (wt\%) of $2.28 \mathrm{Al}, 0.63 \mathrm{Zn}, 0.37 \mathrm{Mn}$ and $\mathrm{Mg}$ balance was used as a substrate. Specimens with dimensions of $\Phi 16 \mathrm{~mm} \times 4 \mathrm{~mm}$ were polished with waterproof abrasive paper from $400 \#$ to 1200\#. The pretreatment was alcohol cleaning for $120 \mathrm{~s}$, acetone cleaning for $90 \mathrm{~s}$, acid polishing for $30 \mathrm{~s}$ and $\mathrm{HF}$ soaking $480 \mathrm{~s}$. A great deal of distilled water was used to rinse the specimens after per cleaning. The final step was to blow the specimens by hot air.

The conversion coating forming process was formulated by an orthogonal experiment. The optimal technical parameters were $5 \mathrm{~g} / \mathrm{L}$ neodymium nitrate $+5 \mathrm{ml} / \mathrm{L} \mathrm{H}_{2} \mathrm{O}_{2}$ (30\%) for $7 \mathrm{~min}$ immersion at $40{ }^{\circ} \mathrm{C}$, and $\mathrm{pH}=6.5$.

The post-treatment process was soaking in the homemade alumina sol at $22^{\circ} \mathrm{C}$, followed by drying for $1 \mathrm{~h}$ at $60{ }^{\circ} \mathrm{C}$ and sintering for $0.5 \mathrm{~h}$ at $150{ }^{\circ} \mathrm{C}$.

The microstructures were observed by an ESCAN VEGA II scanning electron microscope (SEM) equipped with an oxford INCA Energy 350 energy dispersive X-ray spectrometer (EDS). The phase compositions were characterized by a Rigaku D/max 2500PC X-ray diffraction (XRD) using $\mathrm{Cu} \mathrm{K} \alpha$.

$\mathrm{X}$-ray photoelectron spectroscopy (XPS) measurement was carried out in an XSAM800 spectrometer and Al Ka $(1486.6 \mathrm{eV}) \mathrm{X}$-ray radiation was used in the experiments. The data was fitted with XPSPEAK4.1.

Electrochemical tests (potentiodynamic polarization and OCP) were carried out at room temperature in $3.5 \mathrm{wt} \%$ $\mathrm{NaCl}$ solution by a CHI660D electrochemical workstation with a three-electrode system. The system consists of a reference electrode (a saturated calomel electrode), a counter electrode (a platinum foil) and a working electrode. Potentiodynamic polarization experiments were performed at a scan rate of $1 \mathrm{mV} / \mathrm{s}$.

An immersion test was carried out in $3.5 \mathrm{wt} \% \mathrm{NaCl}$ aqueous solution, which was used to evaluate the difference in anti-corrosion resistance between substrates and the coated sample. The test temperature was $22{ }^{\circ} \mathrm{C}$, maintained constant by the air conditioning of the laboratory. The immersion test duration was from $1 \mathrm{~h}$ to $48 \mathrm{~h}$. The morphology and composition was characterized by SEM and EDS, respectively.

The mass of the samples before and after immersion were measured by an electronic balance. The mass gain was determined by the following formula: $W_{\mathrm{g}}=\left(W_{2}-W_{1}\right) / A$, where $W_{1}(\mathrm{mg})$ and $W_{2}(\mathrm{mg})$ are the mass before and after immersion respectively, $A\left(\mathrm{~cm}^{2}\right)$ is the surface area of the specimen.

\section{Results and Discussion}

\subsection{Formation process of Nd-based conversion coating}

Fig.1a shows the mass gain curve and the OCP curve of the sample during immersing in the conversion solution. The mass gain curve reveals the relationship between conversion time and coating thickness, while the OCP curve indicates the relationship between self-corrosion potential $\left(E_{\text {corr }}\right)$ and the corrosion resistance of the Nd-based conversion coating. The trends of the two curves are comparatively similar. They are fluctuant and can be classified into three stages according to their crests and valleys. Obviously, the first peak value is greater than that of the second peak. The formation process can be separated into three stages according to the two curves.

The initial stage $(0 \sim 30$ s) is (I) dissolution of $\mathrm{Mg}$ alloy $^{[21]}$.

$\mathrm{Mg}-2 \mathrm{e} \rightarrow \mathrm{Mg}^{2+}$

With the dissolution, the two curves decreased, the next reaction is:

$$
\begin{aligned}
& 2 \mathrm{H}_{2} \mathrm{O}+2 \mathrm{e} \rightarrow \mathrm{H}_{2} \uparrow+2 \mathrm{OH}^{-} \\
& \mathrm{H}_{2} \mathrm{O}_{2}+2 \mathrm{e} \rightarrow 2 \mathrm{OH}^{-}
\end{aligned}
$$

At this time, a number of $\mathrm{OH}^{-}$are dissolved in the solution.

The second stage $(30 \sim 420$ s) is (II) formation of Nd-based conversion coatings.

The solubility product of $\mathrm{Nd}(\mathrm{OH})_{3} \quad\left(K_{\mathrm{sp}}=1.9 \times 10^{-21}\right)$ is much less than that of $\mathrm{Mg}(\mathrm{OH})_{2}\left(K_{\mathrm{sp}}=1.8 \times 10^{-11}\right)$. When a large amount of $\mathrm{OH}^{-}$is scattered in the conversion solution, $\mathrm{Nd}(\mathrm{OH})_{3}$ is first separated from the solution and attached on the substrate.

$$
\begin{aligned}
& \mathrm{Nd}^{3+}+3 \mathrm{OH}^{-} \rightarrow \mathrm{Nd}(\mathrm{OH})_{3} \downarrow \\
& \mathrm{Mg}^{2+}+2 \mathrm{OH}^{-} \rightarrow \mathrm{Mg}(\mathrm{OH})_{2} \downarrow
\end{aligned}
$$

At this stage, as the immersion time continues, a compact and homogeneous $\mathrm{Nd}$-based conversion layer is slowly formed on the substrate, as shown in Fig.1b. Potential increases slightly with the coating formed. A tiny drop at approximately $100 \mathrm{~s}$ is due to uneven coverage of the film.

The third stage is (III) extra-deposition attaching and coating dropping. 


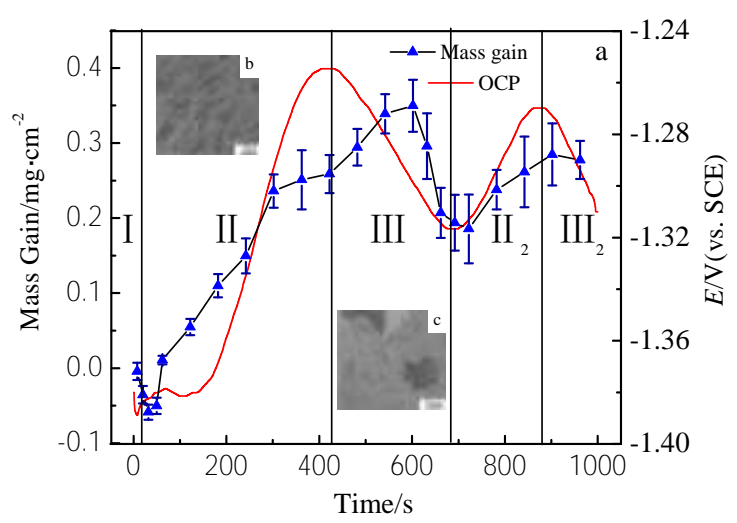

Fig. 1 Mass gain curves and OCP curve of samples immersed in conversion solution

As the layer becomes thicker, the internal stress among "the crack-mud" also increases. When it is larger than the adhesive force, the layer would drop down, as shown in Fig.1c. The decline of OCP demonstrates the dropping stage. Earlier in this stage, the speed of extra-deposition attaching is faster than that of dropping; as a result, the mass of the coating still increases. Then the extra-attaching would cause dropping, and reduce coating mass.

When a considerable area of the matrix is exposed again in the solution, it enters the subsequent formation stage. The trends of mass gain curve and OCP curve after $660 \mathrm{~s}$ correspond with this view. The OCP curve illustrates the subsequent best self-corrosion potential is worse than the first one. In addition, the dropping and second forming in different parts of the substrate surface would result in different thickness and quality. Therefore, the primary best layer is regarded as the best $\mathrm{Nd}$-based conversion coating in the entire formation process.

\subsection{Chemical composition of Nd-based conversion coating}

Fig.2 shows the morphology and composition of the Nd-based conversion coating. The compact and uniform conversion coating with tiny cracks is obtained by the chemical conversion treatment. The atomic fraction (at\%) of $\mathrm{O}, \mathrm{Mg}, \mathrm{Nd}$ is $73.97,13.77,12.26$, respectively. $\mathrm{Mg}$ comes from the matrix, $\mathrm{Nd}$ and $\mathrm{O}$ from the solution, and a few $\mathrm{O}$ from the air.

Fig. 3 shows the XPS spectra of the Nd-based conversion coatings. The binding energy (BE) scale is calibrated with the adventitious $\mathrm{C}$ 1s $(284.4 \mathrm{eV})$ signal, and the BE of these peaks almost coincide with the reference value ${ }^{[22]}$. The results of the analysis are collected in Table 1. The survey spectrum in Fig.3a reveals the coatings mainly consist of $\mathrm{O}$, $\mathrm{Mg}$ and $\mathrm{Nd}$, and their atomic fraction (at\%) are 73.52, 12.73, 13.75, respectively, which perfectly agreed with the EDS results in Fig.2. The high resolution spectra of single element are shown in Fig. 3b 3d. As shown in
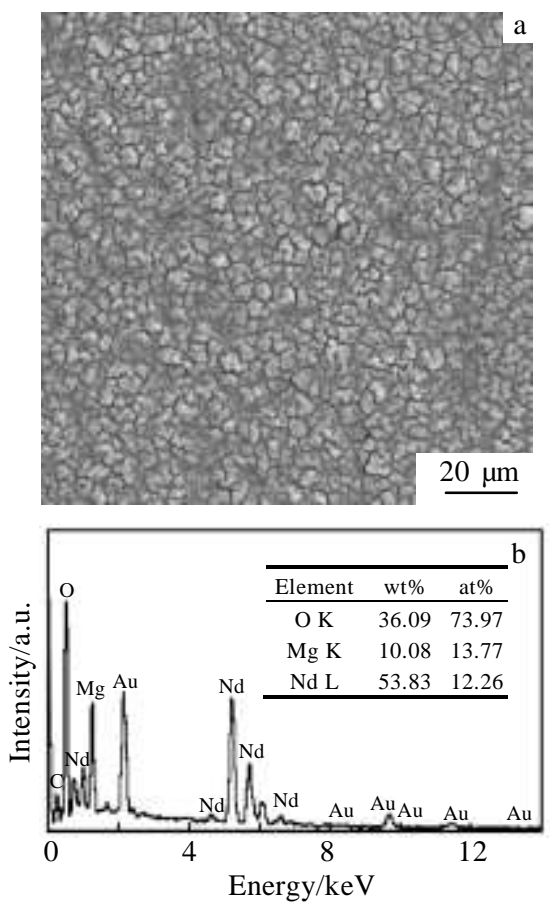

Fig. 2 SEM image (a) and EDS results (b) of Nd-based conversion coating on AZ31 Mg alloy obtained in the optimal forming process

Fig. $3 \mathrm{~b}$, the $\mathrm{Nd} 3 \mathrm{~d}_{2 / 3}$ and $\mathrm{Nd} 3 \mathrm{~d}_{2 / 5}$ peaks are measured elaborately. It corresponds with $\mathrm{Nd}^{3+}$, indicating that the conversion coating is consisted of $\mathrm{Nd}_{2} \mathrm{O}_{3}$ and the $\mathrm{BE}$ of these oxides is $1003.5 \mathrm{eV}$ and $981.7 \mathrm{eV}$. The $\mathrm{O} 1 \mathrm{~s}$ peaks in Fig. $3 \mathrm{c}$ associate with $\mathrm{Nd}_{2} \mathrm{O}_{3}(531.3 \mathrm{eV})$ and $\mathrm{MgO}(529.3$ $\mathrm{eV})$. In addition, the peak area reveals a large number of $\mathrm{Nd}_{2} \mathrm{O}_{3}$ and a small number of $\mathrm{MgO}$. The $\mathrm{Mg} 2 \mathrm{p}$ spectrum corresponds with $\mathrm{MgO}(49.9 \mathrm{eV})$.

\subsection{Corrosion performance of $\mathrm{Nd}$-based conversion coating in $3.5 \mathrm{wt} \% \mathrm{NaCl}$ aqueous solution}

Fig. 4 shows the morphology of the substrate immersed in $3.5 \mathrm{wt} \% \mathrm{NaCl}$ aqueous solution for different time. Fig.4a is the morphology of the substrate immersed for $1 \mathrm{~h}$ in $3.5 \mathrm{wt} \% \mathrm{NaCl}$ aqueous solution, where a few mud-crack products are formed on the partial area of the substrate. In Fig. $4 \mathrm{~b}$ and $4 \mathrm{c}$, with the passage of time, the surface of the substrate is gradually covered with the cracky corrosion products, and some corrosion product particles adhere to the surface. After $48 \mathrm{~h}$ immersion, a large amount of loose and irregular corrosion products are produced by corrosion reactions, and a lot of corrosion product flakes appear in the container. EDS was employed to make out the elements of the corrosion products on the substrate immersed for $24 \mathrm{~h}$. Each element of corrosion products is scheduled by wt $\%$ and at $\%$ in Fig.5. The corrosion products are mainly made 

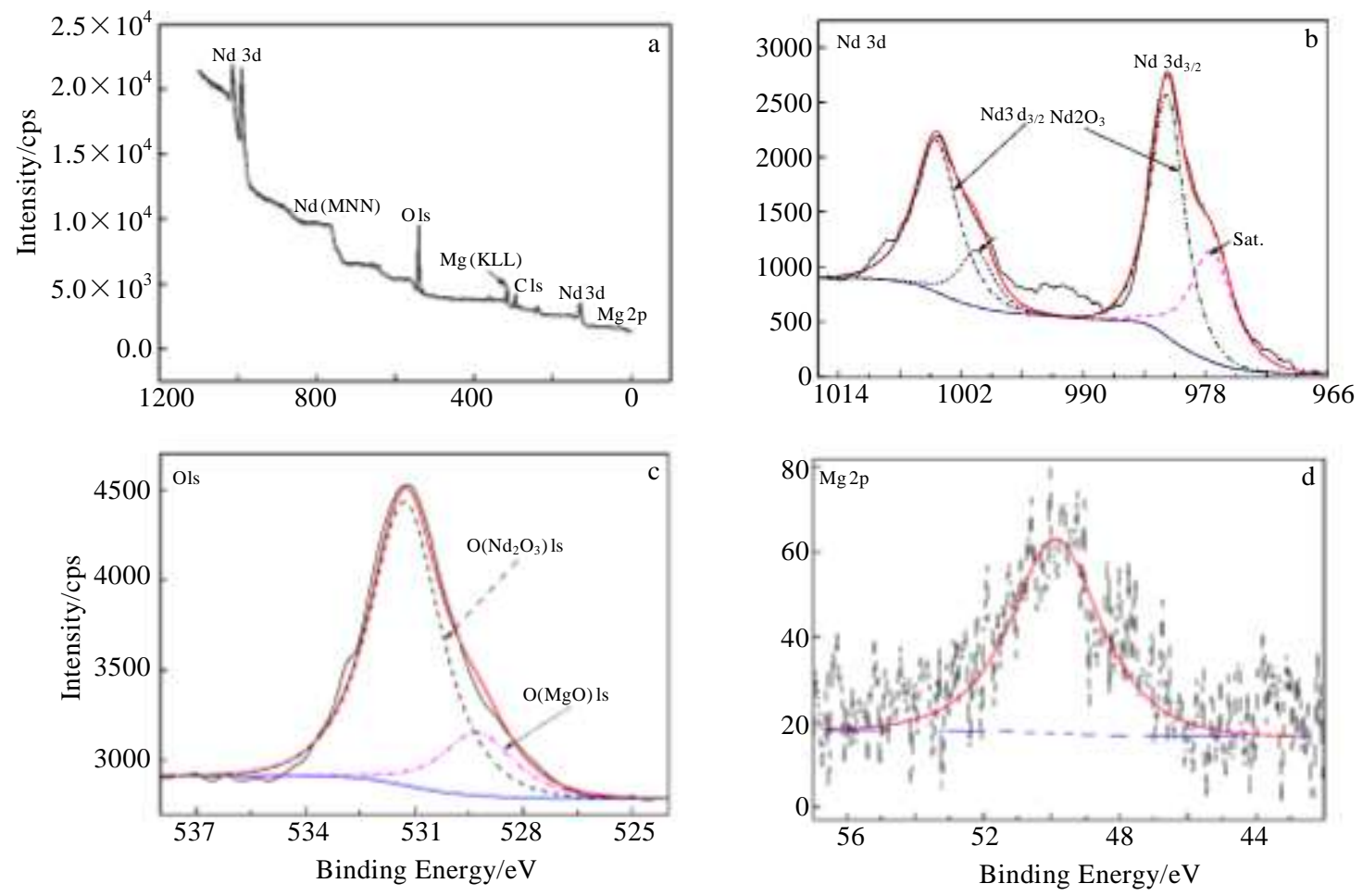

Fig. 3 XPS spectra of samples treated by Nd-based conversion solution: (a) the survey spectra, (b) the high resolution spectra of Nd 3d, (c) the high resolution spectra of $\mathrm{O} 1 \mathrm{~s}$, and (d) the high resolution spectra of $\mathrm{Mg} 2 \mathrm{p}$

Table 1 XPS results of surface element compositions of Ndbased conversion coating (at \%)

\begin{tabular}{cccc}
\hline Elements & $\mathrm{O}$ & $\mathrm{Mg}$ & $\mathrm{Nd}$ \\
\hline Content & 73.52 & 12.73 & 13.75 \\
\hline
\end{tabular}

of $\mathrm{O}, \mathrm{Mg}, \mathrm{Al}, \mathrm{Cl}$. Al comes from the matrix and $\mathrm{Cl}$ mainly from $\mathrm{NaCl}$ solution.

Fig.6 shows the morphology of the treated sample with an optimal technical process immersed in $3.5 \mathrm{wt} \% \mathrm{NaCl}$ aqueous solutions. There are nearly no variations of the Nd-based conversion coatings after immersed for $1 \mathrm{~h}$ in Fig.6a. With the immersion continuing, $\mathrm{NaCl}$ aqueous solution gradually erodes the protective film. After $24 \mathrm{~h}$ immersion, as shown in Fig.6c, some tiny protective coating particles drop off from the matrix. At the same time, a bit of white substance begins to appear on the coating. From then on, white corrosion products gradually deposit on the coatings especially cracks. But the Nd-based conversion coating effectively prevents the corrosion of substrate. EDS of the Nd-based coated sample immersed in $3.5 \mathrm{wt} \% \mathrm{NaCl}$ aqueous solution for $24 \mathrm{~h}$ was investigated for the comparison with EDS of the matrix under the same condition. As shown in Fig.7, besides $\mathrm{Mg}$, $\mathrm{O}$ and $\mathrm{Cl}$, some $\mathrm{Nd}$ exist in the conversion coating, which illustrates corrosion products have not completely covered the Nd-based conversion coating.
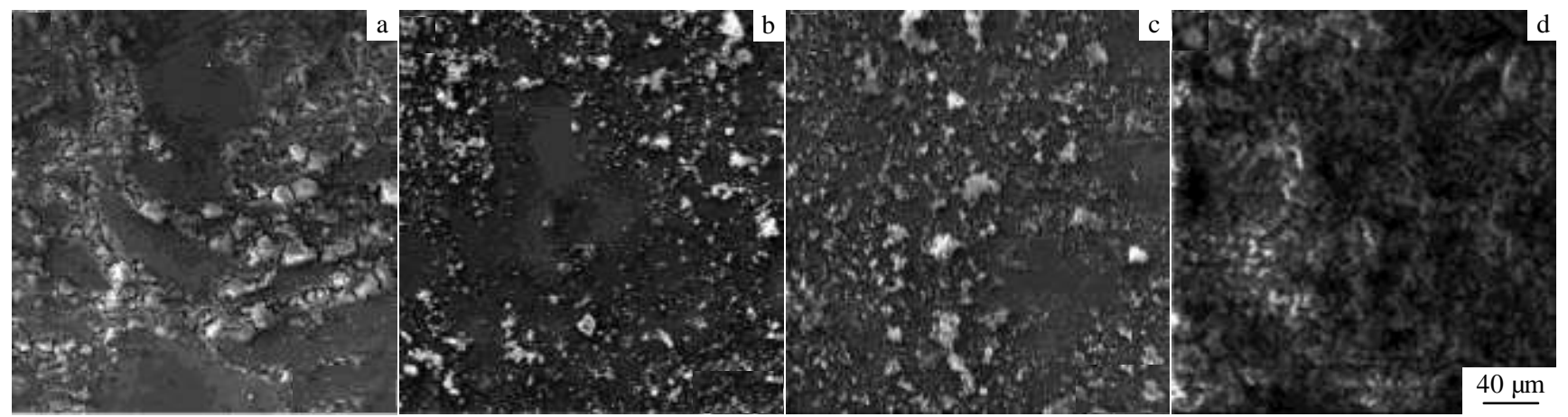

Fig. 4 SEM images of the bare samples immersed in $3.5 \mathrm{wt} \% \mathrm{NaCl}$ aqueous solution for $1 \mathrm{~h} \mathrm{(a),} 12 \mathrm{~h} \mathrm{(b),} 24 \mathrm{~h}(\mathrm{c})$, and $48 \mathrm{~h} \mathrm{(d)}$ 


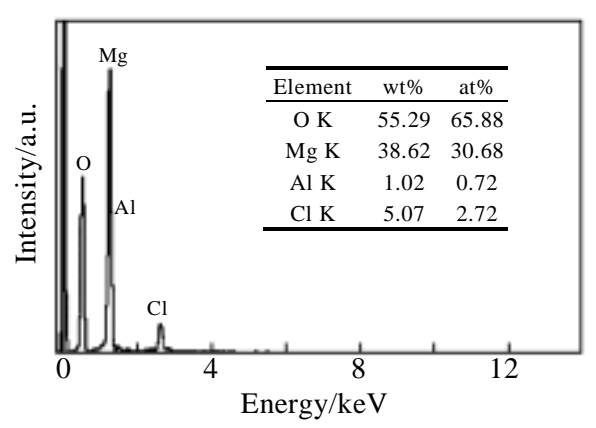

Fig. 5 EDS results of the untreated samples immersed in $3.5 \mathrm{wt} \%$ $\mathrm{NaCl}$ aqueous solution for $24 \mathrm{~h}$

\subsection{Influence of sol-gel post-treatment}

Chemical conversion coating treatments are usually used as surface pretreatment. Alumina sol is adopted as the post-treatment in this experiment. Morphology, composition and performance of the post-treated Nd-based conversion coating were studied by SEM, EDS, XRD and electrochemical experiment.

Fig.8 shows the morphology and composition of the post-treated conversion coating. The post-treated conversion coating has a different morphology compared to the untreated conversion coating in Fig.2. The mud is bigger and the crack is wider. The inset in Fig.8a is the magnified BSE image showing that the Nd-based conversion coating is covered with alumina sol coating, which means AZ31 substrate is separated from the outer effectively. EDS of the post-treated conversion coating demonstrates that $\mathrm{Al}$ is found in the post-treated conversion coating. Other elements in the $\mathrm{Nd}$-based conversion coating still exist in the post-treated coating.

The phase composition of the coated sample and post-treated sample was analyzed by XRD, as shown in Fig.9. Except for $\mathrm{Mg}$ substrate, broad-shaped peak of $\mathrm{Nd}_{2} \mathrm{O}_{3}$ from $21^{\circ}$ to $29^{\circ}$ is found in Fig9b and 9c, broad-shaped peaks of $\mathrm{Al}_{2} \mathrm{O}_{3}$ from $10^{\circ}$ to $20^{\circ}$ are found in Fig.9c, which illustrates that the conversion coating on the substrate is an amorphous structure ${ }^{[20,21]}$. The results of the XRD patterns correspond with the results from EDS and XPS mentioned above.

Fig.10 shows the OCP for the samples recorded during the immersion time in $3.5 \mathrm{wt} \% \mathrm{NaCl}$ aqueous with an interval of $1 \mathrm{mV}$. Values of the coated AZ31 and post-treated one are much more positive than that of the untreated specimen all the time. The OCP of the substrate laxly increases from an initial value of $-1.520 \mathrm{~V}$ to a value of $-1.510 \mathrm{~V}$ after immersing for $1000 \mathrm{~s}$. The change of OCP of the coated sample can be divided into two stages. In the first stage, for the post-treated sample, an obvious increase from $-1.070 \mathrm{~V}$ to $-0.866 \mathrm{~V}$ is observed within the first $50 \mathrm{~s}$, possibly due to the self-repairing function of the Nd-based conversion coating ${ }^{[21]}$. Then the OCP increases slowly and keeps a stable value of $\sim-0.840 \mathrm{~V}$. Similarly, the OCP for the coated sample also has two stages, but it is about 200 $\mathrm{mV}$ lower in the stable state compared with that of the post-treated sample. The change of the value of OCP can be employed to evaluate the electrochemical stability and
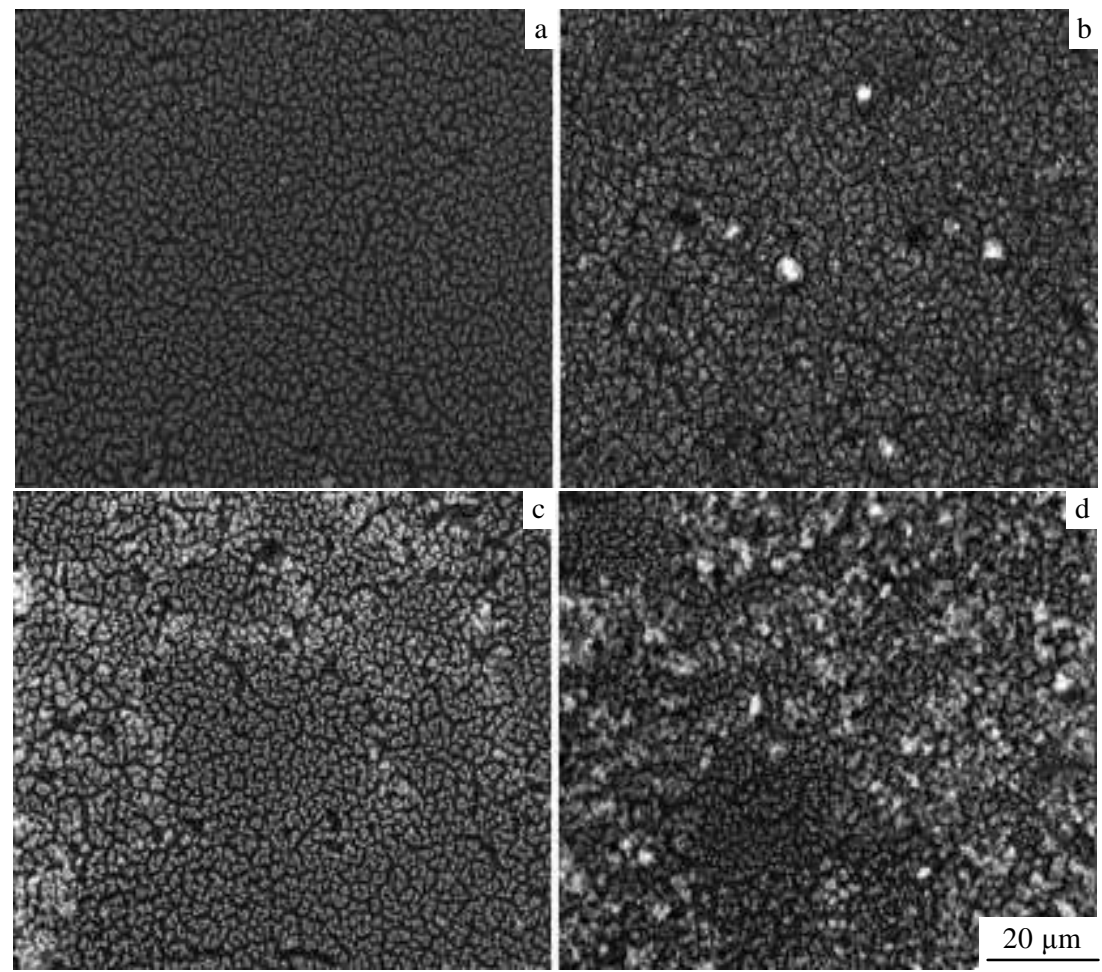

Fig. 6 SEM images of the coated samples immersed in $3.5 \mathrm{wt} \% \mathrm{NaCl}$ aqueous solution for $1 \mathrm{~h} \mathrm{(a),} 12 \mathrm{~h}$ (b), $24 \mathrm{~h}$ (c), and $48 \mathrm{~h}$ (d) 


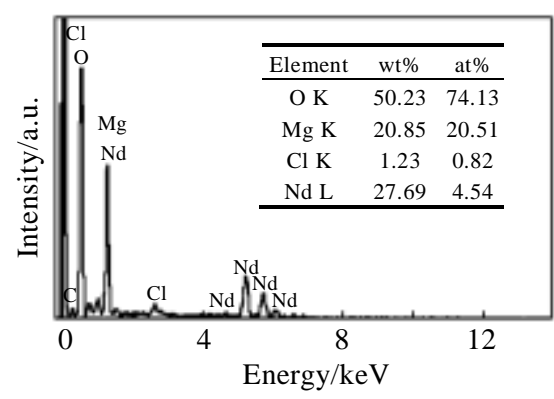

Fig. 7 EDS results of the coated samples immersed in $3.5 \mathrm{wt} \%$ $\mathrm{NaCl}$ aqueous solution for $24 \mathrm{~h}$
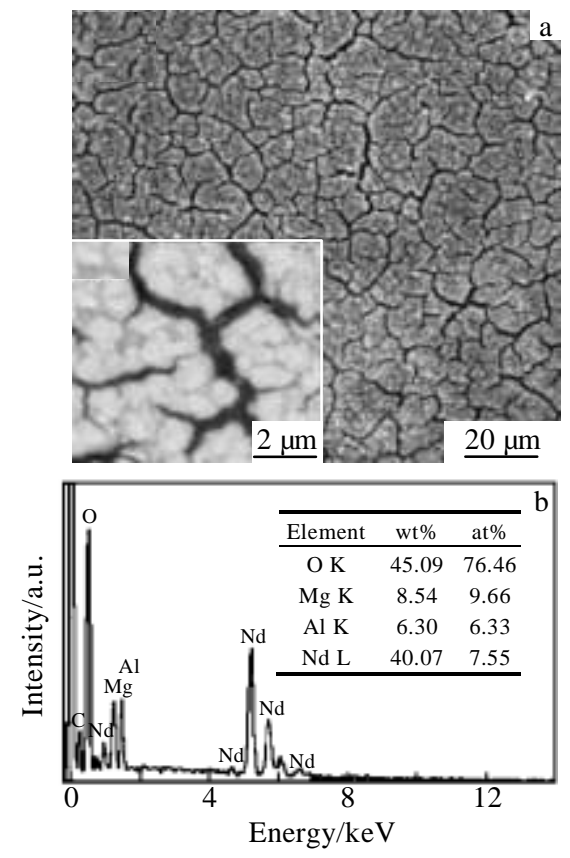

Fig. 8 SEM image (a) and EDS results (b) of the post-treated Nd-based conversion coating on AZ31 Mg alloy

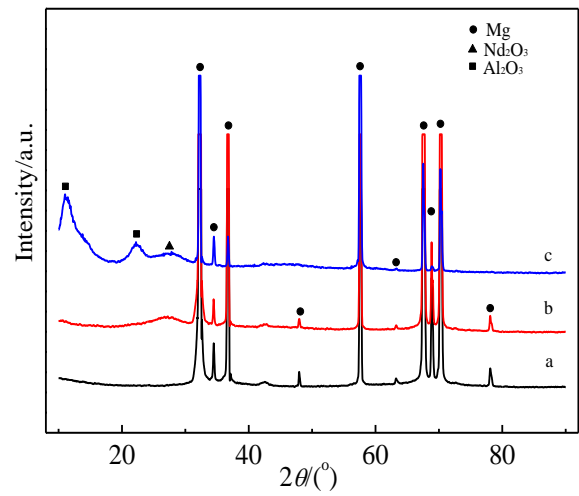

Fig. 9 XRD patterns of different treated samples (a-the bare sample, b-the coated sample, and c-the post-treated sample)

corrosion process of samples during immersion ${ }^{[23]}$. A more positive OCP value demonstrates a better anti-corrosion resistance; thus, there is an obvious improvement of anticorrosion resistance of the AZ31 coated with Nd-based

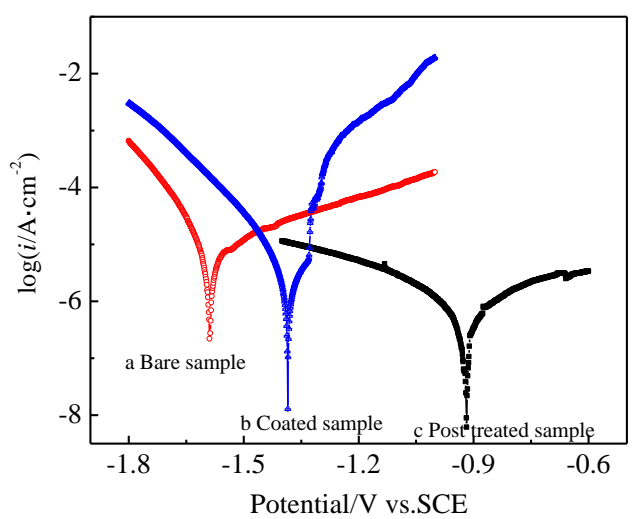

Fig.10 OCP curves of different treated samples (a-the bare sample, b-the coated sample, and c-the post treated sample)

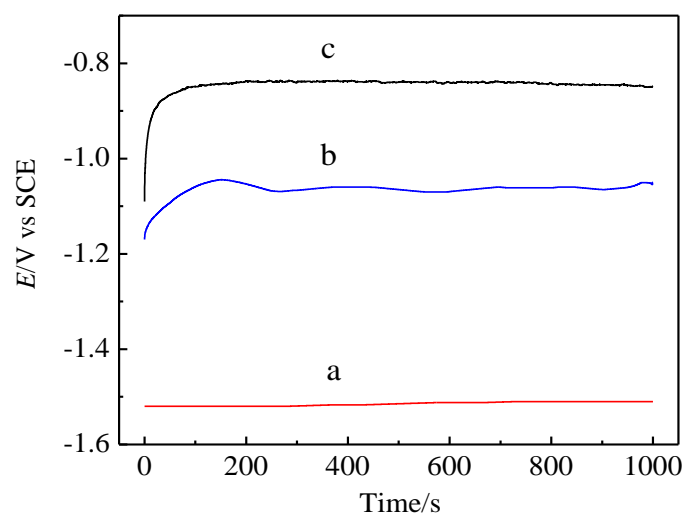

Fig. 11 Tafel curves of different treated samples (a-the bare sample, b-the coated sample, and c-the post-treated sample)

Table 2 Corrosion potential and corrosion current density obtained from potentiodynamic polarization curves

\begin{tabular}{ccc}
\hline Sample & $E_{\text {corr }} / \mathrm{V}$ & $i_{\text {corr }} \mu \mathrm{A} \cdot \mathrm{cm}^{-2}$ \\
\hline Bare sample & -1.558 & 6.880 \\
Coated sample & -1.385 & 1.676 \\
Post-treated sample & -0.918 & 0.734 \\
\hline
\end{tabular}

conversion coatings and the post-treated one.

Potentiodynamic polarization curves for untreated and treated substrates in $3.5 \mathrm{wt} \% \mathrm{NaCl}$ solution at room temperature can be observed in Fig.11. Table 2 gives a summary of the corrosion potential and corrosion current densities as calculated from extrapolation of the tafel plots. The corrosion potentials for the bare sample, the coated sample and the post-treated coated sample are $-1.588 \mathrm{~V}$, $-1.385 \mathrm{~V}$ and $-0.918 \mathrm{~V}$, respectively. The corrosion potential of post-treated coated sample is $203 \mathrm{mV}$ higher than that of coated AZ31 and $670 \mathrm{mV}$ higher compared with non coated AZ31. The coated sample also performs a much lower corrosion current density. There are approximately one order of magnitude decreasing between the coated 
sample and the uncoated sample. These results indicate that corrosion resistance of $\mathrm{Nd}$-based coated AZ31 $\mathrm{Mg}$ alloy is much better than that of uncoated AZ31 Mg alloy.

\section{Conclusions}

1) The formation of Nd-based conversion coating is a cyclic process consisted of dissolution, formation and dropping. The primary best layer is considered as the best Nd-based conversion coating in the entire formation process.

2) The main composition of this rare-earth conversion coating is $\mathrm{Nd}_{2} \mathrm{O}_{3}$ and $\mathrm{MgO}$.

3) The post-treated Nd-based conversion coating is composed of $\mathrm{Al}_{2} \mathrm{O}_{3}$ and $\mathrm{Nd}_{2} \mathrm{O}_{3}$. Otherwise, the post-treated Nd-based conversion coating has a more reasonable microstructure and better anti-corrosion performance.

4) The Nd-based conversion coating can provide effective anti-corrosion resistant protection.

\section{References}

1 Murillo-Gutiérrez N V, Ansart F, Bonino J et al. Surface and Coatings Technology[J], 2013, 232: 606

2 Montemor M F, Simões A M, Carmezim M J. Applied Surface Science[J], 2007, 253(16): 6922

3 Atrens Andrej, Song Guang-Ling, Cao Fuyong et al. Journal of Magnesium and Alloys[J], 2013, 1(3): 177

4 Song Guang-Ling, Xu Zhenqing. Electrochimica Acta[J], 2010, 55(13): 4148

5 Hamdy A S, Butt D P. Electrochimica Acta[J], 2013, 108: 852

6 Zhao Zhenwei, Teng Xinying, Zhou Guorong et al. Rare Metal Materials and Engineering[J], 2014, 43(4): 791

7 Liu Yuping, Li Tingting, Li Jing et al. Rare Metal Materials and Engineering [J], 2014, 43(4): 1013 (in Chinese)

8 Nong Deng, Song Dongfu, Qi Wenjun et al. Rare Metal
Materials and Engineering [J], 2013, 42(5): 1062 (in Chinese)

9 Wang Guixiang, Wang Yangyang, Wu Shun. Rare Metal Materials and Engineering [J], 2014, 43(7): 1764 (in Chinese)

10 Lee Y L, Chu Y R, Li W C et al. Corrosion Science[J], 2013, 70: 74

11 Zhang Dingfei, Gou Yinning, Liu Yuping et al. Surface and Coatings Technology[J], 2013, 236: 52

12 Birbilis Nick, Howlett Patrick C, Macfarlane Douglas R et al. Surface and Coatings Technology[J], 2007, 201(8): 4496

13 Chen Xiao-Bo, Zhou Xian, Abbott Trevor B et al. Surface and Coatings Technology[J], 2013, 217: 147

14 Chen Xiaoming, Li Guangyu, Lian Jianshe et al. Applied Surface Science [J], 2008, 255(5): 2322

15 Van Phuong Nguyen, Moon Sungmo, Chang Doyon et al. Applied Surface Science[J], 2013, 264: 70

16 Hamdy Abdel Salam, Butt D P. Electrochimica Acta[J], 2013, 97: 296

17 Elsentriecy Hassan H, Azumi Kazuhisa, Konno Hidetaka. Electrochimica Acta[J], 2007, 53(2): 1006

18 Rudd Amy L, Breslin Carmel B, Mansfeld Florian. Corrosion Science [J], 2000, 42(2): 275

19 Cui Xiufang, Jin Guo, Yang Yuyun et al. Applied Surface Science [J], 2012, 258(7): 3249

20 Levy Galit, Aghion Eli. Acta Biomaterialia[J], 2013, 9(10): 8624

21 Yu Shengxue, Cao Jingyu, Chen Ling et al. Transactions of Nonferrous Metals Society of China[J], 2008, 18(S): 349

22 Moulder J F, Stickle W F, Sobol P E eds. Handbook of X-Ray Photoelectron Spectroscopy[M]. Minnesota: Physical Electronics Inc, 1995: 186

23 Zhang Hua, Yao Guangchun, Wang Shulan et al. Surface and Coatings Technology[J], 2008, 202(9): 1825

\section{AZ31 镁合金钕基转化膜研究}

赵丁藏 ${ }^{1}$, 张丁非 ${ }^{1,2}$, 刘渝萍 ${ }^{3}$, 胡光山 ${ }^{1}$, 沟引宁 ${ }^{1,4}$, 潘复生 ${ }^{1,2}$

(1. 重庆大学 材料科学与工程学院, 重庆 400045)

(2. 重庆大学 国家镁合金材料工程技术研究中心, 重庆 400044)

(3. 重庆大学 化学与化工学院, 重庆 400044)

(4. 重庆理工大学, 重庆 400054)

摘 要: 通过化学转化成膜在 AZ31 镁合金表面制备了钕基转化膜。利用称重实验和 OCP 测试研究了钕基转化膜的成膜过程, 利用 SEM, EDS 和 XPS 表征了膜层形貌, 微观结构和组成成分。研究了空白样品与镀膜样品在质量分数 $3.5 \% \mathrm{NaCl}$ 溶液中浸泡不同时间 后样品表面形貌和成分。结果表明钕基转化膜可以有效的降低 $\mathrm{AZ} 31$ 镁合金在 $\mathrm{NaCl}$ 溶液中的腐蚀速率。利用 XRD 和电化学测试了经 过后处理以后的钕基转化膜的成分和耐蚀性能，结果说明后处理可以进一步改善钕基转化膜的腐蚀性能。

关键字: AZ31 镁合金; 钕基转化膜; 成膜过程; 腐蚀; 后处理

作者简介: 赵丁藏, 男, 1990 年生, 硕士生, 重庆大学材料科学与工程学院, 重庆 400045, 电话: 023-65112491, E-mail: zhaodingzang @foxmail.com 